\title{
El trabajo del editor y la pauta en medios online chilenos
}

\author{
María Francisca Greene-González ${ }^{1}$ \\ María José Lecaros-Menéndez²
}

Recibido: 2014-06-30

Enviado a pares: 2014-06-30
Aprobado por pares: 2014-07-24

Aceptado: 2014-08-02

DOI: 10.5294/pacla.2015.18.2.11

Para citar este artículo / To reference this article / Para citar este artigo

Greene-González, M.F., Lecaros-Menéndez, M.J. Junio de 2015. El trabajo del editor y la pauta en medios online chilenos. Palabra Clave 18(2), 588-613. D0I: 10.5294/pacla.2015.18.2.11

\section{Resumen}

La siguiente investigación se propone estudiar la figura del editor en algunos diarios online chilenos y su participación en la pauta periodística. La hipótesis inicial de trabajo es que el modo de trabajar la pauta en los diarios online es muy diferente a los de los diarios en papel. La metodología utilizada fue la entrevista en profundidad a siete editores de diarios online y la observación participante en tres de estos medios. Los resultados de la investigación permitieron concluir que la forma de trabajar la pauta en los diarios online es muy diferente a como se hace en los diarios en papel, que el editor juega un papel distinto al de los medios tradicionales y que los diarios digitales chilenos todavía son poco independientes de sus versiones en papel.

\section{Palabras clave}

Prensa, editor, medios electrónicos (Fuente: Tesauro de la Unesco).

1 Periodista y Doctora en Ciencias de la Información por la Universidad Complutense, profesora de Fundamentos de la Comunicación y Ética Periodística de la Facultad de Comunicación de la Universidad de los Andes, Santiago, Chile.fgreene@uandes.cl

2 Periodista y Doctora en Opinión Pública por la Universidad de Navarra, profesora de Ética Periodística de la Facultad de Comunicación de la Universidad de los Andes, Santiago, Chile. mlecaros@uandes.cl 


\section{The Work of the Editor and the Norms for Chilean Online Media}

\section{Abstract}

The following research is to study the figure of the editor in some online Chilean newspapers and their participation in the journalistic norms. The initial hypothesis is that the way that the norms work in online newspapers is very different from those of the daily paper. The methodology used was an in-depth interview to seven editors of online newspapers and participant observations in three of these media. The results of the investigation led to the conclusion that the way to work the norms in the online newspaper is very different than its daily paper, the editor plays a different role from traditional media and online Chilean newspapers are still less independent from their paper versions.

\section{Keywords}

Newspaper, editor, electronic media (Source: Unesco Thesaurus). 


\section{0 trabalho do editor e a pauta em meios on-line chilenos}

\section{Resumo}

A seguinte pesquisa estuda a figura do editor em alguns jornais on-line chilenos e sua participação na pauta jornalística. A hipótese inicial de trabalho se refere ao modo de trabalhar a pauta nos jornais on-line, o qual é diferente ao dos jornais impressos. A metodologia utilizada foi a entrevista em profundidade a sete editores de jornais on-line e a observação participante em três desses meios. Os resultados da pesquisa permitiram concluir que a forma de trabalhar a pauta nos jornais on-line é muito diferente à forma como se faz nos jornais impressos, nos quais o editor desempenha um papel diferente ao dos meios tradicionais e que os jornais digitais chilenos ainda são pouco independentes de suas versões em papel.

\section{Palavras-chave}

Imprensa, editor, meios eletrônicos (Fonte: Tesauro da Unesco). 


\section{Introducción}

El periodismo está en cambio. Las tecnologías actuales han forzado a los periodistas a adaptarse a un nuevo entorno que modifica modos y técnicas de reporteo, de verificación de datos, de construcción y de difusión de las noticias y de participación e interacción con los ciudadanos. La interactividad, la multimedialidad y el nacimiento de una nueva temporalidad caracterizada por la inmediatez son rasgos que definen a los diarios online y tienen como efecto trasformaciones en el trabajo profesional.

Esta investigación propone estudiar el papel de los editores en el trabajo de pauta en tres diarios online de Chile. El estudio de las rutinas de trabajo permite descubrir semejanzas y diferencias en el modo de producir la información entre los antiguos y los nuevos soportes. El supuesto inicial de la presente investigación es que el trabajo de la pauta -y el papel que el editor tiene en ella en un soporte online- debería tener características distintas a la de los medios offline.

Se ha elegido estudiar la rutina de la pauta porque la bibliografía ha solido encontrar en ella relaciones interesantes con la producción de la noticia, la línea editorial y la calidad. Además, esto permite también entender el papel que juegan los periodistas y las relaciones que establecen con su editor; es una rutina que se da en un "ambiente" físico y "social" (Quandt, 2008) con una dimensión de "procedimientos” y, por tanto, fácilmente observable; es una rutina en la que el aporte intelectual y la toma de decisiones marca fuertemente la diferencia en el producto final.

La hipótesis de esta investigación es que, en los diarios chilenos observados, aunque el editor trabaja la pauta con diferencias formales importantes -espacio físico, tiempos, procedimientos-, esta es aún poco propia, contiene menos novedades que las que se esperarían de un nuevo medio y es menos independiente/autónoma de la del soporte papel. Se consideró necesario para confirmar esta hipótesis, además de la revisión bibliográfica, hacer entrevistas a siete editores de medios online chilenos y realizar observación participante en tres medios. 


\section{Los editores y la reunión de pauta en los medios de papel y en los medios online}

Internet "no es la tecnología más disruptiva, sí la de mayor impacto" (Paul, 2008). Esta afirmación puede ser aplicada respecto de las rutinas informativas. En los medios online, al menos inicialmente, pareciera que las rutinas más clásicas han cambiado. Interesa revisar someramente qué trabajo hacen hasta hoy los editores y en qué consistió la rutina de la pauta en los medios offline.

Los editores de los diarios offline tuvieron un papel relevante en la producción de la noticia. Definidos por la literatura como gatekeepers, a ellos correspondía tomar "la decisión final sobre la selección informativa" (Puente, Edwards \& Delpiano, 2014). Dirigían la reunión de pauta, tomaban la decisión final respecto de los entrevistados, seleccionaban temas, jerarquizaban. Asumían también tareas concretas como verificar y corregir; llegaban incluso a titular la nota hecha por el periodista. Decidían: hacían cambios, remplazaban noticias, redefinían un foco, etc. Representaban al director del medio y eran responsables del contenido (cfr. Sancho, 2004; Shoemaker \& Vos, 2009; Greene, 2014).

Con la aparición de las nuevas tecnologías y los medios online, desde la bibliografía académica se reitera la importancia del editor y se propone que este debe adquirir un mayor protagonismo y responsabilidad (Meyers, 2010; Kovach \& Rosenstiel, 2001). Desde una dimensión más empírica, esta figura parece diluirse en los medios online. Sin embargo, en el caso chileno se mantiene la denominación de "editor" en los diarios estudiados y hay tareas específicas que se asocian a ese cargo.

La pauta -editorial meeting entre los sajones- es una instancia privilegiada en la producción de la noticia. Esta rutina ha parecido ser una solución eficiente a esas circunstancias que parecen acompañar el trabajo periodístico. Los llamados "segundos clásicos" de la disciplina de la comunicación (Fishman, Tuchman, Gitlin, Gans, Epstein, Schudson, Molotoch y Lester) resumen esas circunstancias: 1) un suministro infinito de materia prima, 2) tiempos y espacios limitados por la hora de cierre, 3) una organi- 
zación con staff o personal escaso, 4) la necesidad de restringir los gastos de la empresa informativa y 5) la aparición de empresas periodísticas con fines de lucro y, por lo tanto, la competencia entre los medios (Greene, 2012).

Frente a cada una de estas circunstancias que se presentan con carácter de dificultad, los periodistas aplican "consideraciones” que deben ser fácilmente racionalizadas. De este modo, decidir si agregar una noticia, dejarla de lado o reemplazarla por otra se argumenta con una razón convincente que permita tomar una decisión con rapidez. Las consideraciones deben ser rápida y fácilmente aplicables, las opciones deben hacerse sin mucha deliberación: las consideraciones simples ayudan a los periodistas a evitar la excesiva incertidumbre sobre si han elegido las opciones apropiadas (Gans, 1979; Lecaros \& Greene, 2012).

Así, fue habitual que los medios hicieran una o varias reuniones diarias para definir qué material informativo se incluiría y aplicar criterios de jerarquización, foco, fuentes y ubicación en el medio. Es el momento en el que parecieran contestarse esas tres preguntas fundamentales de las rutinas: ¿qué requiere la audiencia?, ¿qué es factible que procese el medio? y ¿qué materia prima está disponible por parte de las fuentes? (Shoemaker \& Reese, 1991). Para los editores chilenos, la pauta está considerada como la primera de las rutinas y es el momento de la jornada a la que otorgan mayor importancia (Lecaros \& Greene, 2012; De Fontcuberta, 1999); es el momento en que "se toman decisiones que afectan a los ciudadanos y a las instituciones sociales" (Pellegrini, 1989).

Esta rutina en los medios offline tiene un espacio físico donde se realiza, un tiempo definido y procedimientos delimitados. Habitualmente consiste en una reunión temprano en la mañana en la que participan editores y el director del medio (antes, cada editor se ha reunido con sus periodistas). Muy estructuradas en el mundo norteamericano, menos en el latinoamericano, su objetivo es el mismo: una suerte de "remate" del reducido espacio del diario para aquellas noticias con mayor "noticiabilidad" propuestas por los distintos editores para sus secciones. Lo más anhelado: lograr aparecer en la primera página. A esta primera reunión le siguen una o dos más en la tarde, ya que la información sigue y muchas veces es necesario replantear 
la selección y jerarquización, cuestión que permanece abierta hasta la hora de cierre (Cowley, 2008).

En Chile el procedimiento de pauta es similar. El estudio de Puente et al. (2014) lo describe con dos reuniones (una matutina y otra en la tarde) en las que se definen temas, foco y jerarquización. El editor sigue ciertas noticias planteadas en la pauta durante todo el día, resuelve conflictos y reenfoca cuando es necesario, para lo cual se apoya muy fundamentalmente en el llamado por celular para consultas/consejos, en Twitter y WhatsApp. La presencia del editor es más continua y permanente gracias a estas tecnologías de lo que era antes, cuando el periodista debía resolver solo y tomaba decisiones sobre la marcha (Lecaros \& Greene, 2012; Gronemeyer, 2012). Así, la pauta online parece no cerrarse con la reunión de la tarde, sino que se "alarga" gracias a los cambios que posibilitan estas tecnologías hasta la hora de cierre de los medios.

El estudio de Puente et al. (2014) concluye que el ingreso de la tecnología a las salas de redacción "no ha afectado todavía a las rutinas periodísticas, sino que más bien ha reforzado la figura del editor como gatekeeper".

A los medios online se les "define" por ese listado de posibilidades: la interactividad, la multimedialidad y esa nueva temporalidad caracterizada por la inmediatez. Se puede presumir que estos rasgos que caracterizan a los diarios online producirán cambios en sus modos de trabajo.

La tecnología en la web tiene dos caras. Por una parte, facilita y simplifica, permite acortar tiempos, hace innecesarias ciertas rutinas, hace accesible un conocimiento acabado de la competencia, permite obtener enorme cantidad de datos y opiniones en poco tiempo; extiende, en fin, las posibilidades para hacer mejor periodismo. Por otra parte, las tecnologías también enfrentan al medio online a realidades para las cuales aún no posee rutinas establecidas: un lector que es también autor, por ejemplo, o a acciones antes rutinarias que hoy adquieren una nueva connotación y deben ser repensadas: la capacidad ( $y$ facilidad técnica) para cortar y pegar material de diferente naturaleza: fotos, audios y videos y material disponible en la web. 
En la aún breve experiencia sistematizada de medios online, hay cuestiones interesantes de destacar para efectos de este estudio.

En materia de editores, su figura, con este u otro nombre, sigue vigente, al menos como una persona con conocimientos de managment y conocimientos de la noticia (Brannon, 2008). El editor sigue ejerciendo su papel de gatekeeper, aunque para algunos autores este concepto esté declinando y esté siendo reemplazado por el papel de gatewatching, esa nueva capacidad para observar todo el material que entra y seleccionarlo y destacarlo de acuerdo con los intereses de la comunidad a la cual se dirige el medio (Bruns, 2006; 2008). Los estudios recientes chilenos muestran algo semejante. Hablan de "pauta compartida”, en la que los editores continúan teniendo un rol de liderazgo, aunque hoy se sume la participación de personas naturales: "gran parte de la pauta informativa diaria se hace cargo de los intereses de las personas, responde a ellos y se construye con ellos" (Greene, 2014). Los editores están más expuestos a los usuarios y lo que estos ofrecen pasa a ser parte de su toma de decisiones. Respecto del antiguo fact-checking, la corroboración de información, se afirma que se ha debilitado (Paterson \& Domingo, 2008), aunque en Chile se alude a que es aún una tarea (no siempre lograda) del editor (Greene, 2014).

Estudios ingleses han llegado a la conclusión de que la creación del contenido ha dejado de ser exclusiva de una élite y la participación pública en las pautas y los propios contenidos es creciente (Blank, 2013; Dutton $\&$ Blank, 2013). Un estudio de caso en Inglaterra, que incluyó encuestas a ciudadanos y periodistas, introduce el concepto de "quinto poder" que se atribuye a la capacidad del público de generar sus propios contenidos en la red. Estos contenidos son recogidos por el tradicional "cuarto poder" dando origen a una nueva ecología de las noticias (Blank, Dutton; Newman, 2012).

\section{Metodología}

Para realizar este análisis fue necesaria la revisión de bibliografía desarrollada en el punto anterior, que permitió definir conceptos y términos básicos para la comprensión de este estudio. 
Esta investigación se desarrolló durante diciembre de 2013 y enero de 2014. Fue exploratoria (Hernández, 2003), pues provee datos que pueden ser clasificados, ordenados, analizados e interpretados para descubrir ideas y relaciones nuevas (Vieytes, 2004). Además, fue descriptiva (Hernández, 2003), para así predecir -aunque sea en un grado mínimo- el comportamiento del objeto (Vieytes, 2004).

Según el método utilizado, fue cualitativa, orientada a captar el origen, el proceso y la naturaleza de los significados de los actos de los sujetos investigados, que brotan de la interacción (Ruiz Olabuénaga, 2003). Su intención fue entender los acontecimientos, acciones, normas y valores desde la perspectiva de los propios sujetos que los producen y experimentan, preguntándose qué piensan, cómo viven o experimentan un cambio en sus hábitos y costumbres (Vieytes, 2004).

Fueron seleccionados siete medios representativos de los diarios nacionales que han adoptado las nuevas tecnologías en su modo de trabajo diario. A ellos se aplicaron entrevistas del tipo semiestructurada, basadas en una guía de preguntas y asuntos específicos (Hernández, 2003), también llamadas entrevistas estandarizadas abiertas (Canales, 2006). Las entrevistas duraron aproximadamente una hora y media, en donde se realizó un cuestionario con quince preguntas relacionadas con las decisiones, la pauta, los contenidos, calidad, fuentes, tiempo y espacio y rutinas periodísticas. La entrevista en profundidad se ha validado como un método de levantamiento de material de estudio sustentado en el valor atribuible a respuestas honestas y significativas en una conversación cómoda y sin esquemas fijos o categorías de respuestas predefinidas (Ruiz Olabuénaga, 1999; Guerrero, 2001; Blasco \& Otero, 2008; Taylor \& Bogdan, 2000).

Los entrevistados fueron: Sebastián Campaña de emol.com, Alejandro Osorio de latercera.com, Samuel Romo de lanacion.cl, Juan Carlos González de lasegunda.com, Ximena Torres de terra.cl, Hugo Infante de lacuarta. com y Elizabeth Harries de pulso.cl.

En tercer lugar, se llevó a cabo una observación participante en tres medios: emol.com, lanacion.cl y lasegunda.com. 
Tradicionalmente, el objetivo de la observación participante ha sido detectar las situaciones en que se expresan y generan los universos culturales y sociales en su compleja articulación y variedad. La aplicación de esta técnica supone que la presencia (la percepción y experiencia directa) ante los hechos de la vida cotidiana de la población garantiza la confiabilidad de los datos recogidos y el aprendizaje de los sentidos que subyacen a dichas actividades (Guber, 2001).

Aunque los resultados se centran fundamentalmente en lo encontrado en estos tres medios -emol.com, lasegunda.com y lanacion.cl- las encuestas a esos y otros cuatro diarios online han sido muy útiles para reafirmar tendencias y entender mejor lo que se observó en los diarios online y lo que se recoge de las entrevistas.

Se eligieron estos tres diarios dadas las características y tradiciones diversas a las que pertenecen: líneas editoriales e historias distintas (Paterson \& Domingo, 2008). Interesaba descubrir hasta qué punto su modo de trabajar la pauta estaba más influido por sus diferencias que por la semejanza de ser online. Se quería verificar si, a pesar de las diferencias, el concepto de pauta y el trabajo del editor en la pauta era o no similar. Muy brevemente conviene destacar las diferencias entre estos diarios:

lanacion.cl es un diario digital; su versión papel cerró en noviembre de 2013 (ese mismo año apareció online), después de años de circulación con un modelo propio: siempre representó el pensamiento del gobierno de turno. Aún hoy, en la entrevista, Romo define su medio como uno que "no tiene sólo una mirada cliquera (sic) como Terra o Emol. Tenemos una función más amplia, además de dar garantía a todos los sectores de que el diario no está abanderado con ninguna tendencia (...) tenemos un sentido social, de información plural, con datos atractivos que le sirven al ciudadano común y corriente". Lo integra un equipo de 15 a 18 personas. Posee oficinas más grandes que las de lasegunda.com y mejor equipadas. Los periodistas comienzan su trabajo a las 7:00 a. m., hora en la que suben la información. 
emol.com es el portal de noticias más importante del país. Inició sus actividades como parte de la empresa El Mercurio. En la entrevista, el editor aclara que Emol se define como autónomo dentro de la empresa desde 2009 y que se reporta directamente a la vicepresidencia ejecutiva y no al director de El Mercurio. Se define como un "sitio web de noticias que busca tráfico, bajo ciertos parámetros y línea editorial asociada a El Mercurio". Pero afirma, al mismo tiempo, que sus lectores lo asocian a El Mercurio y esto los hace, como medio, mantenerse dentro "de los márgenes mercuriales". Emol tiene 21 periodistas que trabajan en siete grandes canales: Chile, Actualidad, El Mundo, Deporte, Cultura y Espectáculo, Mujer, Tecnología y Multimedia (cada canal tiene tres periodistas).

lasegunda.com es una propuesta que se inició en coordinación con el diario en papel, hasta el punto de que su editor confiesa que va primero a la reunión de pauta del diario papel a las 8:30 de la mañana y después llega a su medio. En esa pauta revisa qué le parece relevante de lo que llevará el diario ese día, puesto que, afirma, "nosotros nacimos para destacar los contenidos de La Segunda (papel)... somos una sección del diario, pero con independencia para trabajar". En los últimos años trabajó en coordinación estrecha con la editora de Espectáculo de La Segunda, hicieron proyectos juntos y vio cómo se beneficiaban ambos.

La investigación da como resultado la constatación de la hipótesis de que la pauta en línea es distinta de la de los medios tradicionales, como también el rol del editor en la pauta.

\section{Resultados}

Las entrevistas realizadas y la observación participante arrojan resultados interesantes que confirman la hipótesis y siguen la línea de la bibliografía revisada.

Estos resultados se agrupan en los siguientes grupos temáticos: 1) ambiente de los medios online: aquellos aspectos detectados en la observación participante, como organización física y espacio, horarios, turnos, número de personas que trabajan e interacción entre ellas, entre otros; 2 ) pauta: 
hay o no reunión, la forma que tiene, su periodicidad, qué "alimenta" a la pauta, la "no pauta” y la "pauta semanal", y 3 ) el editor y su trabajo, área de decisiones, lo que incluye el contenido noticioso, la autonomía de este respecto del papel, la medición y su incidencia en la inclusión y permanencia de los contenidos, la edición, relación con los periodistas, verificación, temas sensibles.

\section{Ambiente en los medios online}

La observación participante permitió una visión in situ de las respuestas de los editores.

\section{lasegunda.com}

La sala donde trabajan no es muy grande: hay ocho puestos de trabajo con un computador cada uno, incluido el puesto del editor, que está en el medio. Además hay un televisor permanentemente encendido en 24 Horas de TVN y una emisora de radio, Cooperativa. Cuando esta trasmite noticias importantes, el editor se para y sube el volumen para que todos puedan escuchar.

A las 8:00 a.m. no se ve mucha gente, solo están el editor y un periodista.

El editor comienza a mirar en su computador la información de agencias internacionales para ver si hay alguna noticia importante, aunque no las usa a menos de que sean informaciones sobre países vecinos relacionados con temas fronterizos. También revisa agencias de noticias nacionales.

Alrededor de las 9:00 a. m. comienzan a llegar los demás periodistas y se empieza a actualizar la página.

En el diario hay dos turnos: dos periodistas llegan a las 8:00 a. m. y se preocupan de tener actualizada la portada. El siguiente turno entra las 9:00; son periodistas que se preocupan solo de su sección y, si ven otra noticia, se la ofrecen a los que están preocupados de la portada. "Lo fundamental -dice el editor- es mantener la comunicación entre los colegas”. 
Desde las 8:00 se comienzan a subir noticias para poner en la primera nota. Si no hay nada muy interesante se espera un poco, pero la idea es hacerlo antes de las 9:00.

El blog de opinión se renueva todos los días: los columnistas mandan su columna al editor y él las sube o se busca alguna interesante que haya salido en el diario offline y se quiera destacar en la versión online.

A las 10:00 llega el periodista encargado de las redes sociales, que copia el titular que sale en portada y lo sube en Facebook y Twitter.

A esa hora ya se han hecho tres cambios de noticias desde que comenzaron a trabajar.

El editor cuenta que a veces tienen que subir noticias no tan importantes para ir entregando datos nuevos a las personas.

"A las noticias que suben les tratan de hacer cambios para que no sean iguales a los demás medios, pero igual la base es parecida”, aclara el editor.

El periodista encargado de redes sociales va subiendo a Twitter todas las noticias que los periodistas actualizan.

Se van preguntando entre ellos las cosas que han publicado.

El editor también va subiendo noticias y tiene su sección, que es Ciencia y Tecnología.

\section{lanación.cl}

En lanacion.cl se observa una oficina mucho más grande y equipada que la de La Segunda online. Cuenta con cinco televisores que muestran distintos canales: Canal 13, TVN, Google Analytics y CNN. Por Google Analytics están monitoreando cuántas visitas reciben y cuáles son las noticias más leídas.

A las 8:30 a. m., el editor se encuentra trabajando en una nota y tres periodistas le preguntan constantemente por noticias; hay bastante inte- 
racción. El editor pregunta a sus periodistas cómo van con sus respectivas notas, si ya las subieron y en qué lugar las pondrán.

Los periodistas están constantemente atentos a lo que se muestra en TVN.

Los periodistas de lanación.cl comienzan a trabajar a partir de las 7:00 a. $\mathrm{m}$. y van actualizando inmediatamente su sitio a partir de la información que dan los canales de televisión, otros medios online y las agencias como UPI, EFE, UNO, de donde obtienen notas, imágenes y videos.

Para complementar lo que obtienen de los demás medios, intentan dar otro enfoque, buscando más información y trabajando con material de archivo, para que quede algo más o menos distinto.

La periodista encargada de política cuenta que trabajan las notas que sacan de las agencias. Asegura que no hacen "copiar y pegar", sino que las "traducen", les dan vuelta, para que no queden tal cual y puedan entenderse mejor. También cuenta que generalmente cada uno de los periodistas sube entre cuatro a seis noticias diarias. Las notas internacionales son más abundantes, ya que, según cuenta, son sacadas directamente de las agencias.

La periodista encargada de las secciones Salud, Educación y País llega a las 9:00 informada de lo que tiene que llegar a hacer y, durante el transcurso del día, va agregando datos a las notas y complementando con un reporteo por teléfono, buscando información propia, pero sin ir al lugar, ya que eso le quitaría mucho tiempo.

lanacion.cl cuenta con un móvil, que se encarga de llevar y traer a los periodistas y al fotógrafo que eventualmente salen para reportear.

Se observa a los periodistas reportear por teléfono, preguntando la información necesaria para la redacción de las noticias.

Los periodistas cuentan con grabadoras para ir teniendo un resguardo de lo que las fuentes telefónicas les van contando. 
En general, el trabajo es independiente, pero siempre hay interacción con el editor, quien va guiando a los periodistas e informando acerca de lo que va sucediendo, para que la parrilla informativa se vaya completando y sea lo más eficaz y expedita posible. Según lo que se puede observar, el editor está mucho más presente en el trabajo de sus periodistas que en el caso de lasegunda.com. El editor toma una nota ya publicada y la va modificando en Word, cambiando conectores, dando vuelta a algunas cosas; su trabajo es más bien un asunto de estilo. El editor decide en qué lugar del diario van las notas que los periodistas escriben.

La periodista encargada de redes sociales cuenta cómo maneja las cinco redes sociales con las que cuenta el diario: Facebook, Twitter, Google+, Tumblr y Pinterest, donde se suben las noticias más importantes del día, pero de distintas formas. Lo que más usan es Twitter, donde se suben noticias más seguido, modificando los titulares de acuerdo con los trending topics. En Facebook la idea es generar opinión e interacción con los seguidores, siempre evitando el contacto con los trolls, que se dedican a atacar, a los cuales no se les responde. Este medio sirve también para que los seguidores puedan alertar a los periodistas acerca de alguna falla en lo publicado. Cuenta que no se borra ninguno de los comentarios que se le hacen a las publicaciones. En Google+, Tumblr y Pinterest se juega mucho con las imágenes y fotos llamativas de las noticias. Estas redes generalmente no se actualizan muy seguido, pero sí se ocupan de tener presencia y uno que otro contacto con seguidores, que no son muchos en estos casos.

\section{emol.com}

El equipo de emol.com está constituido por cerca de 50 personas, de las cuales 21 son periodistas que reportean, solo si es un tema importante que puede convertirse en titular y que tendrá repercusiones durante el día. Los periodistas que salen a la calle están constantemente comunicándose con los que están en la sala de redacción, para que suban algunos contenidos y se actualice la información.

La labor del editor consiste básicamente en la gestión de contenidos, en ir subiendo las noticias de la portada y actualizándola constantemente según la lectoría y la importancia de la información. Tiene constantemen- 
te una pantalla donde ve la portada de cada una de las secciones del diario online y otra donde va cambiando la portada. En una pestaña aparte está la aplicación de Google Analytics, que le muestra las noticias más visitadas por minuto. Revisa también gráficos donde se muestran distintos diarios nacionales.

Hay una televisión prendida con 24 Horas de TVN.

Un periodista revisa redes sociales y otros medios, también escribe una nota.

Solo en pocas ocasiones algunos periodistas le cuentan al editor las notas que han subido.

Se ve que periodistas de la misma sección coordinan entre ellos y ven lo que necesitan: algunas fotos y fuentes.

Están constantemente todos los periodistas que se encuentran en el lugar revisando las páginas de la competencia: La Tercera, Las Últimas Noticias, Radio Cooperativa, lanacion.cl, soychile.cl, terra.cl.

Cada coordinador revisa ocasionalmente los niveles de lectoría que les entrega la aplicación de Google.

Todos hablan por teléfono. Conversan los periodistas con sus coordinadores cuando suben notas en que hay detalles importantes.

El periodista de la sección internacional reportea a través de agencias y revisa algunos diarios internacionales.

Mientras avanza la hora, cada vez son más los periodistas que se acercan al editor para conversar acerca de sus temas y respectivas noticias. Se nota que realmente este editor es figura de autoridad para sus periodistas. Hay respeto y le hacen caso en lo que dice. 
Algunas notas de los periodistas se complementan con lo que está en la versión impresa de El Mercurio.

\section{Pauta en los diarios online}

La reunión de pauta en el diario online no existe del modo tradicional: se puede hablar de una "no pauta". La descripción más reiterada de la pauta digital es que el editor online o coordinador se reúne varias veces al día con cada periodista. Eso es hacer pauta. Hay que destacar que todos los editores unánimemente valoran este tipo de "no pauta" digital como un momento importante de su trabajo y espontáneamente todos la diferencian -porque la han "vivido" y les parece importante diferenciarla- de la pauta reposada y trabajada del diario papel.

Todos también mencionan otra pauta: la reunión de pauta semanal que todos los medios digitales afirman tener; en ocasiones, también una mensual; en un caso se mencionó la "pauta de la noche" (emol.com).

Hay excepciones. Hay editores de medios online que tienen su homólogo en papel (pulso.cl, latercera.com, lasegunda.com y lacuarta.com) que participan de la pauta matutina del diario offline y luego llegan a reunirse con sus periodistas del diario online y les transmiten las ideas que les parece que valen la pena.

La pauta no tiene un esquema, ni periodicidad, ni lugar fijo. No hay una reunión de pauta de todos juntos: habitualmente es el editor con cada periodista. No hay tampoco un espacio físico, ni un esquema definido, ni una hora determinada. El tiempo apremia a la pauta. La definen como altamente flexible (en términos de contenido y jerarquización); esta flexibilidad está relacionada con los gustos e intereses del lector: "no hay un espacio en que diariamente uno vea pauta con todos los periodistas" (lanacion.cl); "es individual o a lo más de a dos (...) yo veo con cada uno como será el día, ellos llegan y cuentan cómo les fue y vemos por dónde agarramos la noticia" (lanacion.cl); "en la mañana todos los días vemos rápidamente en qué estamos, qué está pasando, para ver si desechamos algunas cosas y nos concentramos en otras" (lacuarta.com); "el tiempo no permite reuniones, 
permite contactos"(emol.com); "no hay una instancia de una o media hora como en los diarios offline, que empiezan a pensar cómo será el día” (emol. com). "Como sabemos qué le gusta a nuestra audiencia y somos pocos, si hay cosas que no funcionan, decidimos que se cambien. (...) A las tres de la tarde nos concentramos en tirar muchas notas. (...) Tenemos la ventaja de que vemos inmediatamente qué ve la gente y eso influye en la pauta, que va cambiando" (lacuarta.com). "Resumiendo, todo es muy flexible, a pesar de que tenemos grandes puntos, vamos cambiando de lugar e incluyendo datos" (lacuarta.com).

En parte importante, el "alimento" de la pauta está dado por los contenidos que llegan y los que se buscan, cuestión que tiene diferencias interesantes con las pautas de medios offline. El alimento de la pauta es infinito: prensa escrita on y offline, radio, televisión -nacional e internacional-, la web con todas sus posibilidades y canales (Twitter, Facebook, WhatsApp), lo que lleva el medio papel, lo que reportean (que es lo menos y habitualmente por teléfono). Todo se agrega: "yo me nutro de todo, todo sirve... la televisión, la radio ... tenemos la libertad de citar a cualquier medio... citamos al medio tanto por nobleza como por responsabilidad" (emol.com); "no salimos a reportear, el trabajo está muy anclado acá" (lasegunda.com); los periodistas "actúan como si fueran periodistas de agencia, hablan todo el día con sus fuentes por teléfono" (lacuarta.com); “Twitter, cada uno (de los periodistas) sigue a sus propias personas... son alertas importantes" (emol.com); "estamos chequeando siempre" (lacuarta.com).

Los contenidos se ven “afectados” (se “bajan”, se eliminan) rápidamente por los sistemas de medición que informan de los gustos del público (los diarios online tienen el sistema Google Analytics, que les permite ver en detalle y con precisión qué noticia fue leída). Si una noticia no es leída, simplemente se baja o se saca. Se ve también afectado el contenido por la línea editorial, que sigue incidiendo y es mencionada espontáneamente por los entrevistados. "Si una noticia está arriba y no me está marcando lo que me debiera marcar, la bajo. Si una nota marca 100 usuarios al minuto, pienso 'no me está dando lo que necesito', por lo importante de la posición, por lo que la bajo y pruebo con otra” (emol.com); "como sabemos qué le gusta 
a nuestra audiencia, si hay cosas que no funcionan, decidimos que se cambien" (lacuarta.com); "permanentemente estamos viendo quién nos lee y qué leen, a veces pueden cambiar la pauta, pero hay notas que aunque no las lea nadie, hay que tenerlas" (latercera.com); "no hemos llegado al punto de subir sólo lo que vende; vamos equilibrando" (lacuarta.com). "Tratamos de cuidar la marca" (lasegunda.com); "no es sólo una mirada 'cliquera' (como otros), tenemos una función más amplia" (lanacion.cl); "la portada tiene dos vertientes editoriales: una es lo que la gente debe leer, donde nosotros metemos cierta línea editorial de El Mercurio; la primera y segunda noticia responden a una decisión editorial y no popular. El resto de las notas las manejamos nosotros" (emol.com).

Todos los medios online informan de una reunión semanal a la que dan enorme importancia. En ella, habitualmente, se hace un balance de la semana en términos de números, de contenidos. Se revisa lo que faltó, se programa la semana que viene de acuerdo con lo previsible y con la contingencia. La revisión del ranking online, tanto propio como de toda la competencia, es un aspecto relevante. La reunión mensual (no mencionada por todos) pareciera tener relación con aspectos más de marketing. "La pauta importante es la que se hace una vez a la semana" (lacuarta.com); "ahí hago un balance de la semana en términos de números, cómo nos fue, qué nos faltó, y proyectamos la semana" (lanacion.cl).

\section{El editor y su trabajo}

Es interesante observar que todos los editores han trabajado anteriormente en las versiones offline de sus respectivos diarios. Tanto en las entrevistas como en la observación participante, la figura del editor está presente y ellos lo saben: "mi función como editor es ver todo lo que están haciendo los periodistas" (lacuarta.com). Aunque no se le distinga rápidamente en términos de ubicación física, de las entrevistas se deduce que tiene roles y rutinas definidas: hace la pauta con cada periodista y todos los entrevistados concuerdan en que la pauta es uno de sus trabajos más importantes.

$\mathrm{Al}$ dar cuenta de su trabajo, los editores afirman hacer solo una "semiedición” respecto de temas sensibles o que antes se definen como impor- 
tantes. Todos los entrevistados dicen no revisar nada antes de subir, y solo pocas cosas una vez que ya están en el ciberespacio. Sin embargo sí chequean la información que llega: "yo monitoreo Twitter, porque es parte de mi función, para ver las cosas que están pasando” (lacuarta.com).

En cambio, tienen todo "el poder" -"yo mando y digo: anda o ve"-para sacar información que no obtiene lectura y para cambiarla de lugar (jerarquía). También definen las temáticas. Algunos afirman revisar textos, solo para ver si cumplen con los requisitos de la web, si llevan hipervínculos, etc.

Los editores también son autónomos respecto del papel (cuando lo hay) y reconocen una línea editorial compartida o propia respecto de la cual han establecido criterios para incluir o excluir noticias (y temas) de acuerdo con ella. Tienen definiciones también respecto de rutinas offline, para las cuales han introducido modificaciones (como la verificación, atribución, rectificación, edición).

Trabajan marcados por la velocidad, la falta de tiempo, la necesidad de que esté rápido la información en la web.

La importancia del editor en la pauta y lo que incluye queda clara en las entrevistas: sugiere focos, entrevistados, hace cambios a lo largo del día y determina si se reportea y qué. Define qué temas incluir y cuáles excluir: "mi rol como editor es dar énfasis en la pauta... me preocupo más de la previa para ver cómo se van a llevar los temas y dónde se van a ubicar, si irán con foto" (emol.com); "la pauta tiene una importancia total, es como la columna vertebral del trabajo del día ... todo mi día transcurre de lo que puse en la pauta y ahí tengo las variables, pero igual tengo la base" (lacuarta.com); "mi primera misión es generar pauta, eso es lo fundamental" (latercera.com); "nos demoraríamos más en mandar un móvil con el periodista, el camarógrafo y el fotógrafo en lugar de tomarlo acá donde se puede hacer una historia mejor" (lanacion.cl); "privilegiamos temas ciudadanos y que le importen a la gente (abusos al consumidor, postulación a subsidios), deporte, tendencias y emprendimientos" (lanacion.cl). 
La edición de los editores online es diferente. Es una edición más referida a qué subir y qué no que a la corrección de estilo o foco. Los entrevistados reconocen que no es exhaustiva (comparada con la del papel): "vamos revisando la información y sugiriendo cambios, pero no es una edición muy exhaustiva, como se hacía en el diario papel, hay menos tiempo... miro más que nada la escritura web, que tenga hipervínculos, que se anexen documentos o videos si los hay" (lanacion.cl); "no se analizan todos los textos como se hace en el papel... es imposible ver todo" (latercera.com).

En cuanto a la autonomía respecto del papel, los contenidos varían entre los diarios. Aquellos que tienen su homólogo en papel reproducen bastantes noticias de allí. Es el caso de latercera.com, lasegunda.com, lacuarta.com y pulso.cl. En cambio, emol.cl, lanacion.cl y terra.cl suelen ser más autónomos. Esta autonomía, en el primer caso, se da con El Mercurio; en los otros dos es total, pues no hay diario offline para comparar.

La autonomía de emol.com es relativa, pues tiene como parte de la línea editorial y como exigencia de la empresa de la que depende (El Mercurio S.A.P) colocar entre las tres primeras notas noticias de la edición en papel de El Mercurio.

La autonomía, sin embargo, no se da entre las mismas publicaciones. Los diarios online suelen informar lo mismo y sobre lo mismo, con variaciones menores. De alguna noticia grande obtienen distintas aristas, en que suelen coincidir porque las fuentes son casi siempre similares.

Las rutinas de los diarios online son más definidas de lo que suele pensarse: respecto del uso del off the record dicen que "con el off no nos arriesgamos si no tenemos algo con cuña" (lanacion.cl). Respecto de las confirmaciones aclaran que "no lo vamos a subir aunque sea de relevancia, prefiero confirmarlo... hay un proceso de verificación porque hay mucho rumor" (emol.com); "no se puede usar Twitter para confirmar una noticia, pero sí para enriquecerla” (latercera.com). Respecto de lo que se lee antes de subir a la web y el tratamiento de ciertas temáticas, agregan: "yo leo aproximadamente el $10 \%$ de las informaciones subidas, son las que aparecen en por- 
tada y temas sensibles relacionados con políticos o religiosos" (emol.com). Respecto de las rectificaciones y los errores señalan: "nosotros rectificamos igual como lo hacen los diarios en papel ... se pone que esa noticia ha sido modificada, hay que hacerlo, no se puede dejar pasar" (lacuarta.com); "trabajamos con un equipo de redes y ellos hacen la corrección” (emol.com).

La velocidad permea todo el trabajo de pauta y toda la labor del editor: "acá todo es muy rápido, si falta algo no se incluye y si es importante se hace una nueva nota con lo que faltó" (lanacion.cl) "todo se resuelve en el momento" (lanacion.cl).

\section{Conclusiones}

Los resultados de las entrevistas y la observación participante permiten obtener cuatro grandes conclusiones:

1. Aunque los diarios comparados tienen diferencias históricas importantes, distintas propuestas periodísticas y líneas editoriales también diversas, comparten ciertas características -en el rol del editor y en el manejo de la pauta- que parecieran indicar que la incidencia de la dimensión online marca más que las diferencias ya señaladas, y que la fuerza de las rutinas de la pauta que todos los entrevistados "vivieron" y valoraron en medios offline los hace aplicar este peculiar modelo de pauta, algo que parece una aplicación forzada de la antigua pauta offline.

2. La figura del editor online no está del todo perfilada. Pareciera que tiene menos "control" sobre los contenidos de la información que la del editor offline: se limita a dar "el pase" con algunas correcciones, para que salga la información a lo largo del día. Las rutinas tradicionalmente relacionadas con la calidad (verificación, atribución, rectificación, edición) se aplican en niveles mínimos y, en cambio, se enfatiza como prioridad (y papel propio del editor) la velocidad para subir la información, para cambiarla de lugar de acuerdo con los intereses que marca el público, para sacarla y para corregirla si es necesario. Algo similar sucede con el reporteo: como este es la excepción, será atribución del editor pedir que se salga a la calle. 
3. La pauta, momento definitorio del diario offline, parece ser una rutina sin mucho sentido tal como se la describe en los diarios online. Los objetivos de la pauta del diario offline -guía para el reporteo, jerarquización de la información en un espacio limitado- no son los objetivos de los medios online, en los que prima la velocidad, el cambio permanente, en los que la noticiabilidad está dada por la lectoría más que por un criterio a priori, y donde no hay límites de espacio (siempre se puede agregar), no hay reporteo propio, no hay "cierre" temporal: siempre se puede corregir, agregar, bajar. La "pauta” parece ser una rutina heredada que no se ha adaptado al nuevo medio. Más adecuada pareciera la pauta semanal, que todos califican de importante y que quizá merece un estudio más detallado puesto que sí parece ser una rutina nueva que puede ser eficiente para este nuevo medio.

4. El diario digital en Chile necesita estudiar su perfil propio y redefinir el rol del editor e idear una rutina que remplace la tradicional pauta. Hay dos problemas clásicos que no solo se mantienen, sino que crecen: el suministro infinito de materia prima hoy se ha agigantado y la escasez de personal se ha hecho más evidente. Sin embargo estos medios parecen haber solucionado el antiguo problema de "tiempos y espacios limitados por la hora de cierre". Sobre estas nuevas circunstancias deben hacer sus propuestas y elaborar las nuevas rutinas para idear una manera de ordenar un caos de información que llega a través de múltiples cauces.

\section{Referencias}

Blank, G., Dutton, W. y Newman, N. (2012). Social media in the changing ecology of news: The fourth and fifth estates in Britain. International Journal of Internet Science, 7 (1), 6-22.

Blank, G. (2013) Who creates content? Information, Communication \& Society, 16(4), 590-612.

Blasco, T. \& Otero, L. (2008). Técnicas conversacionales para la recogida de datos en investigación cualitativa: la entrevista. Nure Inves- 
tigación, 33. Recuperado el 22 de marzo de 2014 de http://www. nureinvestigacion.es/FICHEROS_ADMINISTRADOR/F_METODOLOGICA/ formet_332622008133517.pdf

Brannon, J. (2008). Maximize the medium: Assesing obstacles to performing multimedia journalism in three U.S. newsrooms. En Paterson, C. \& Domingo, D. (Eds.), Making online news: The ethnography of new media production. Nueva York: Peter Lang.

Bruns, A. (2008). The active audience: Transforming journalism from $\mathrm{Ga}$ tekeeping to Gatewatching. En Paterson, C. \& Domingo, D. (Eds.), Making online news: The ethnography of new media production, (pp. 171-184). Nueva York: Peter Lang.

Canales, M. (2006). Metodologías de investigación social. Santiago: Editorial Lom.

Cowley, A. (2008). News production in an Irish Online Newsroom: Practices, process and culture. En Paterson, C. \& Domingo, D. (Eds.), Making online news: The ethnography of new media production, (pp. 45-60). Nueva York: Peter Lang.

De Fontcuberta, M. (1999). Pauta y calidad informativa. Cuadernos de Información, 13, 61-69.

Dutton, W. \& Blank, G. (2013) The emergence of Next Generation Internet users. International Economics and Economic Policy, 10, 83-91.

Gans, H. (1979). Deciding what's news: A study of CBS evening news, NBC nightly news. Nueva York: Random House.

Greene, F. (2012). La objetividad como rutina periodística. Pamplona: Eunsa.

Greene, F. (2014). Los medios bajo la influencia de las plataformas tecnológicas: ¿en qué medida estas afectan en la toma de decisiones de 
los editores chilenos? Revista Estudios sobre el Mensaje Periodistico, 20(1), 113-129.

Gronemeyer, M. (2013). La digitalización y sus efectos sobre las prácticas y productos periodísticos en Chile. Palabra Clave, 16(1), 101-128.

Guber, R. (2001). La etnografía, método, campo y reflexividad. Bogotá: Editorial Norma.

Guerrero, L. M. (2001). La entrevista en el método cualitativo. Santiago: Editorial Universidad de Chile

Hernández, R. (2003). Metodología de la investigación. Ciudad de México: McGraw-Hill.

Kovach, B. \& Rosentiel, T. (2001). The elements of journalism: What newspeople should know and the public should expect. Nueva York: Random House.

Lecaros, M. y Greene, F. (2012). Editores chilenos y rutinas periodísticas: revisión y propuesta para un estudio sobre el cambio en la sala de redacción. Cuadernos.info, Suramérica, 30. Recuperado el 12 de mayo de 2014 de http://cuadernos.uc.cl/uc/index.php/CDI/ article/view/426

Meyers, C. (2010). Journalism ethics: A philosophical approach. Nueva York: Oxford University Press.

Puente, S., Edwards, C. \& Delpiano, M. O. (2014). Modelamiento de los aspectos intervinientes en el proceso de pauta periodística. Palabra Clave, 17(1), 188-210.

Paterson, C. \& Domingo, D. (2008). Making online news: The ethnography of new media production. Nueva York: Peter Lang. 
Pellegrini, S. (1989). Políticas de información. Santiago de Chile: Ediciones Universidad Católica.

Quant, T. (2008). News tuning and content management: A observation study of old and new routines in German Online Newsrooms. En Paterson, C. \& Domingo, D. (Eds.), Making online news: The ethnography of new media production (pp. 77-97). Nueva York: Peter Lang.

Ruiz Olabuénaga, J. (2003). Metodología de la investigación cualitativa. Bilbao: Universidad de Deusto.

Sancho, F. (2004). En el corazón del periódico. Pamplona: Eunsa.

Shoemaker, P. \& Reese, S. (1991). Mediating the message: Theories of influences on Mass Media content. Nueva York: Longman.

Shoemaker, P. \& Vos, T. (2009). The Gatekeeping Theory. Nueva York: Taylor \& Francis.

Taylor, S. \& Bogdan, R. (2000). Introducción a los métodos cualitativos de investigación. Barcelona: Paidós.

Vieytes, R. (2004). Metodología de la investigación en organizaciones, mercado y sociedad. Epistemología y técnicas. Buenos Aires: Editorial de las Ciencias. 